\title{
Do Immigrants Save Less than Natives? Immigrant and Native Saving Behaviour in Australia*
}

\author{
ASADUL ISLAM \\ Department of Economics, \\ Monash University, Victoria, \\ Australia
}

\author{
JAAI PARASNIS \\ Department of Economics, \\ Monash University, Victoria, \\ Australia
}

\author{
DIETRICH FAUSTEN \\ Department of Economics, \\ Monash University, Victoria, \\ Australia
}

\begin{abstract}
The observed wealth differential in favour of native households seems to contradict the analytical presumption of a saving differential in favour of immigrant households. This article seeks to explain the observed differences in wealth through an examination of the respective saving behaviour of immigrants and natives. Quantile regression and semiparametric decomposition methods are used to identify the saving differential and to isolate the factors that contribute to it. The basic finding is that household income is the key to the differential saving pattern. Moreover, decomposition analysis suggests that immigrants have a tendency to save more than natives when compared with Australian-born households with similar characteristics. We also find evidence of heterogeneity in immigrant saving behaviour depending on household types and countries of origin.
\end{abstract}

\section{Introduction}

There is increasing evidence of disparities in the wealth and portfolio behaviour of immigrant and native-born households. Specifically, immigrant households in Australia have recently been shown to hold significantly less wealth than their native counterparts (Cobb-Clark \& Hildebrand, 2006, 2009; Doiron \& Guttmann, 2009; Bauer et al., 2011). This evidence sits uneasily with the set of broad incentives for migrants to maintain a stronger flow of saving

\footnotetext{
*We thank the editor, Professor Denise Doiron, and two anonymous referees, whose suggestions and comments were invaluable in improving the paper. We also thank Deborah Cobb-Clark, Steven Stillman, Chris Worswick and participants in the workshop on 'Consumption and Savings' at Monash University and in the 2009 Australian Conference of Economists for their helpful comments and suggestions. The usual disclaimer applies.

JEL classifications: F22, J61, D10

Correspondence: Jaai Parasnis, Department of Economics, Monash University, PO Box 1071, Narre Warren, VIC. 3806, Australia. Email: jaai.parasnis@ monash.edu
}

than natives, which should manifest in a wealth differential in their favour. It is also difficult to reconcile with the superior wealth-increasing characteristics of migrant households (Doiron \& Guttmann, 2009).

Conjectures and evidence on saving differentials provide mixed signals (Dustmann, 1997; Amuedo-Dorantes \& Pozo, 2002). Precautionary motives sustained by income uncertainty and relative difficulties in accessing welfare benefits are expected to raise immigrant saving propensities relative to similarly positioned native households. Similarly, the probability of return migration (Galor \& Stark, 1990; Dustmann, 1995), geographical separation from family and friends, and peer effects (Maurer \& Meier, 2008) may stimulate the saving motive of immigrants. At the same time, a broad range of factors including current needs and inter-temporal time preferences (Browing \& Crossley, 2001), income and income growth rates, unemployment and insurance opportunities influence the saving patterns of immigrant and native households with ambiguous implications for their relative saving. 
Bauer and Sinning (2011) report that immigrants in West Germany save significantly less than natives. Carroll et al. (1994) do not find any systematic differences by country of origin in the saving patterns of Canadian immigrants, but in a separate study, Carroll et al. (1999) do observe such differences for US immigrants. Bauer et al. (2011) find that in 2002 immigrant households in Australia held approximately \$9000 less wealth than native households (at the median). CobbClark and Hildebrand (2009) and Doiron and Guttmann (2009) corroborate the observed difference in the respective wealth holdings and asset portfolios of immigrant and native households in Australia. Doiron and Guttmann (2009) confirm that the negative wealth gap characterises the entire wealth distribution, increasing in the level of wealth.

Migrants' education advantage and other demographic characteristics should promote saving and lead to larger wealth holdings. According to Bauer et al. (2011), these characteristics are the main drivers of the wealth gap, but they do not translate into a wealth advantage for immigrants. However, they may help to explain why the gap observed in Australia is relatively small.

Labour market outcomes have an a priori ambiguous effect on saving patterns. Migrants in Australia experience lower wages and higher unemployment than the native-born population (Miller \& Neo, 2003). While lower incomes tend to reduce saving, a higher probability of unemployment and greater sensitivity to adverse macroeconomic conditions are likely to stimulate precautionary saving (McDonald \& Worswick, 1999). Conversely, superior income growth may reduce incentives for current saving by immigrant households relative to natives (Miller \& Neo, 2003).

Unlike native households, immigrants have greater opportunities and incentives for holding wealth abroad. They may send remittances to support family and kinship or to fulfil social commitments. They may retain bequests and inheritances and use their savings to acquire and hold assets in their country of origin in the form of housing stock or financial investments. Income uncertainty and the possibility of return migration provide powerful incentives to build up such asset holdings (Osili, 2007; Dustmann \& Mestres, 2010). Consequently, wealth accumulation in the country of residence is unlikely to provide a comprehensive view of immigrant wealth holdings (Amuedo-Dorantes \& Pozo, 2002). Nor are observed wealth differentials within a particular country necessarily indicative of different saving behaviours of immigrants and natives.

The tension between the empirical evidence of wealth differentials, ambiguous findings on relative saving behaviour and indications of superior wealth-increasing characteristics of immigrant compared with native households motivates the present investigation. Specifically, we explore how the relative wealth disadvantage of migrant households in Australia, and the relatively low measured saving that gives rise to it, can be reconciled with the contrasting expectation. To this end, we distinguish two broad categories of potential explanators of saving patterns: household characteristics, in particular the demographic factors that influence labour market outcomes, and household behaviour. Household behaviour is influenced by cultural practices, extended family obligations and differential access to formal and informal insurance arrangements to protect against income shocks (Bonin et al., 2009), the socioeconomic strata in which migrants grew up, the motivation for migration and the probability of return migration (Carroll et al., 1999). These cultural and institutional influences are either specific to immigrants or they affect migrants and natives differentially.

Our main finding is that, ceteris paribus, the saving behaviour of immigrants is not inferior to native households. When we control for covariates, we find that neither the level of saving nor the saving rate in migrant households is lower than in native-born households. At the same time, household characteristics differ systematically between the two groups. Specifically, immigrant households consistently have lower income than native-born households. These results indicate that it is the difference in household characteristics, in particular in income, which accounts for the observed wealth differential between the two groups.

This study complements the work on wealth holdings and asset portfolio composition by Cobb-Clark and Hildebrand (2009) and Doiron and Guttmann (2009) by examining the wealth accumulation process. Our results suggest that the observed wealth differential does not reflect a relatively lower return to the wealthgenerating characteristics of migrants (Doiron \& Guttmann, 2009, p. 33). Rather it reflects 
the inferior labour market outcomes for migrant households as captured in measured income.

\section{Data and Descriptive Statistics}

We use data from the Australian household expenditure surveys (HES) for 1988/89, 1993/94, 1998 and 2003/04. These data provide detailed information about the expenditure, income and household characteristics of a sample of households resident in private dwellings throughout Australia. The spread of the surveys over oneand-a-half decades provides a sufficiently long sample period for investigating saving behaviour. As household surveys rarely report a direct, robust and consistent measure of saving, it is necessary to construct a saving series. Saving can be measured either as the change in the stock of wealth or as the difference between income and consumption flows. Given the cross-sectional nature of the dataset, we use the flow measure of household level saving. We focus on out-ofpocket saving, defined as the difference between consumption and after-tax income. This definition, in turn, requires accurate treatment of income and consumption in the presence of capital gains, mortgages, pension funds and accounting for the durable nature of some consumption items.

\section{(i) Income}

Income comprises cash and in-kind receipts of a regular and recurring nature. It is the sum of wage and salary disbursements, tips, other labour income, farm income, business income (net proprietors income from unincorporated business), net rental income, interest on savings and dividends, and transfer income from government, private institutions and other households, employer and employee contributions to pension funds, inheritance, gifts and other income from family members. Disposable income is defined as total household income minus taxes.

\section{(ii) Capital Gains}

We exclude all capital gains and losses from household income. Differentiating between unrealised and realised gains is problematic, while including a meaningful measure of capital gains in the saving estimates would be difficult because of the high degree of volatility of this component. Therefore, we consider the 'active' component of saving to be represented by the difference between income exclusive of capital gains and consumption. ${ }^{1}$

\section{(iii) Consumer Durables}

It is a matter of controversy whether they should be treated as consumption or investment expenditure. Consumer durables are typically treated as final consumption expenditure when purchased by households. Alternatively, the fact that they generate a stream of services or income that raises future consumption possibilities suggests they should be treated as investment expenditure (Browning \& Lusardi, 1996; Perozek \& Reinsdorf, 2002; Reinsdorf, 2004; Jalava \& Kavonius, 2009). As the total outlay on consumer durables is significant, and because their services satisfy a non-trivial component of consumption demand, there is merit in recognising net acquisitions of consumer durables in consumption spending while also acknowledging their investment role. To this end, we apply the perpetual inventory method to obtain annual expenditure estimates that correspond to the stock of consumer durables (Jalava \& Kavonius, 2009). In view of the underlying ambiguity, and also to analyse the sensitivity of our estimates, we use three alternative specifications of consumption, each including car registration and insurance fees as 100 per cent expenditure for the year, with corresponding specifications for saving (Sav1Sav3).

$1 \mathrm{C} 1$ includes all expenditure on consumer durables for the survey year.

2 C2 includes an imputed value of consumer durables corresponding to a flat 15 per cent depreciation of the stock.

3 C3 excludes all expenditure on consumer durables. This definition uses only non-durable items purchased for the year and applies the depreciation method.

\footnotetext{
${ }^{1}$ We acknowledge that capital gains, even unrealised capital gains, can influence saving through the so-called wealth effect. This effect is illustrated, for instance, by the consumption boom preceding the global financial crisis. The stock market boom had sustained massive increases in spending by reducing the saving rate as households treated capital gains as a substitute for savings. However, Dynan et al. (2004) argue that the focus on active saving is reasonable as long as capital gains are unrealised or do not entirely change the behaviour at the time of the saving decision.
} 


\section{(iv) Housing Expenditure}

Rent paid by households is included in consumption expenditure. Treatment of housing expenditure for owner-occupied households is more complex as they consume equivalent housing services without paying rent while building up equity in real estate. In recognition of this dual effect, mortgage service payments can be decomposed into amortisation, which is treated as saving, and interest which is considered consumption expenditure. Following Reinsdorf (2004) and Dynan et al. (2004), we treat gross-imputed rent as the corresponding housing expenditure. The 2003-2004 survey reports experimental estimates of imputed rent for owner-occupied dwellings. Imputed rents for earlier survey years are estimated by applying the methodology detailed in ABS (2008). Imputed rent is calculated using a hedonic model where rent is a function of the location and dwelling characteristics and the Inverse Mills ratio correcting for selection bias. The Inverse Mills ratio is obtained from a probit model with occupant characteristics as identifying instruments.

\section{(v) Consumption Expenditure}

Consumption equals total household expenditure plus imputed rent for home owners less the sum of: mortgage amortisation payments, expenditure on home capital improvement, life insurance payments and spending on new and used vehicles including running costs (petrol, insurance). This implies that expenditure for houses and vehicles are part of saving in this definition.

\section{(vi) Pension and Superannuation}

Contributions to pension plans are counted as transfers from governments to households. Household and employer contributions to private pension plans in expectation of a future pension are treated as saving and income, respectively. It follows that benefits paid by the plans to retirees are excluded from personal income because they draw down savings balances accumulated in the plan much like withdrawals from a bank account built up by retirees. Only the employer contributions made to the plan are regarded as income (the earnings of the plan are not income). In contrast, benefits obtained by households from other sources such as child/age care benefit are transfer receipts and, hence, income.

Descriptive statistics for migrant and native households from the four expenditure surveys are reported in Table 1. Both saving and income are reported in current Australian dollars per week. The absolute income differential between the two groups is moderate throughout the period though switching sign, changing from approximately 0.8 per cent in favour of migrants (in 1988/89) to 3.6 per cent in favour of native-born households (in 2003/04). With the exception of 1993/94, migrants consistently save less than native-born, although the difference in 1998 is nugatory. The saving differential is robust with respect to the amount of consumer durable expenditure included in saving. Both saving and income differentials increase over time in favour of native-born households. Migrant household heads are consistently older than their native counterparts, with the age difference approximately doubling over the observation period. Migrant households are less likely to have a female head or to be a sole parent, and they are typically larger than native households.

We use a kernel smoothing technique to estimate the saving (Sav1) distributions for each survey year to describe the immigrant-native saving differentials across the distributions. ${ }^{2}$ These distributions are plotted in Figure 1a-d. In 2003/04, the saving distribution of natives is slightly to the right of the immigrants' distribution. No such consistent distributional difference is apparent in the earlier years. The distributions are almost identical in 1988/89.

Figures 2a-d display the difference in weekly saving (Sav1) between immigrants and natives at different quantiles. We also map unconditional quantile regression (QR) coefficients for different quantiles following Firpo (2007). The method allows estimating the unconditional quantile of saving while permitting covariates to match immigrants and natives. We include covariates in the first-stage regression to estimate a propensity score for each household. That propensity score is then used as weight in estimating the unconditional saving at different quantiles. That is, we reweight the empirical distribution of the outcome variable using weights that equalise the empirical distributions of the explanatory variable. The raw data estimates of quantiles indicate that with the exception of 1993/94, immigrants consistently save considerably less than natives at each quantile of the saving distribution. Inclusion of covariates to match immigrants and natives,

2 The distributions look similar when we consider Sav2 and Sav3. 


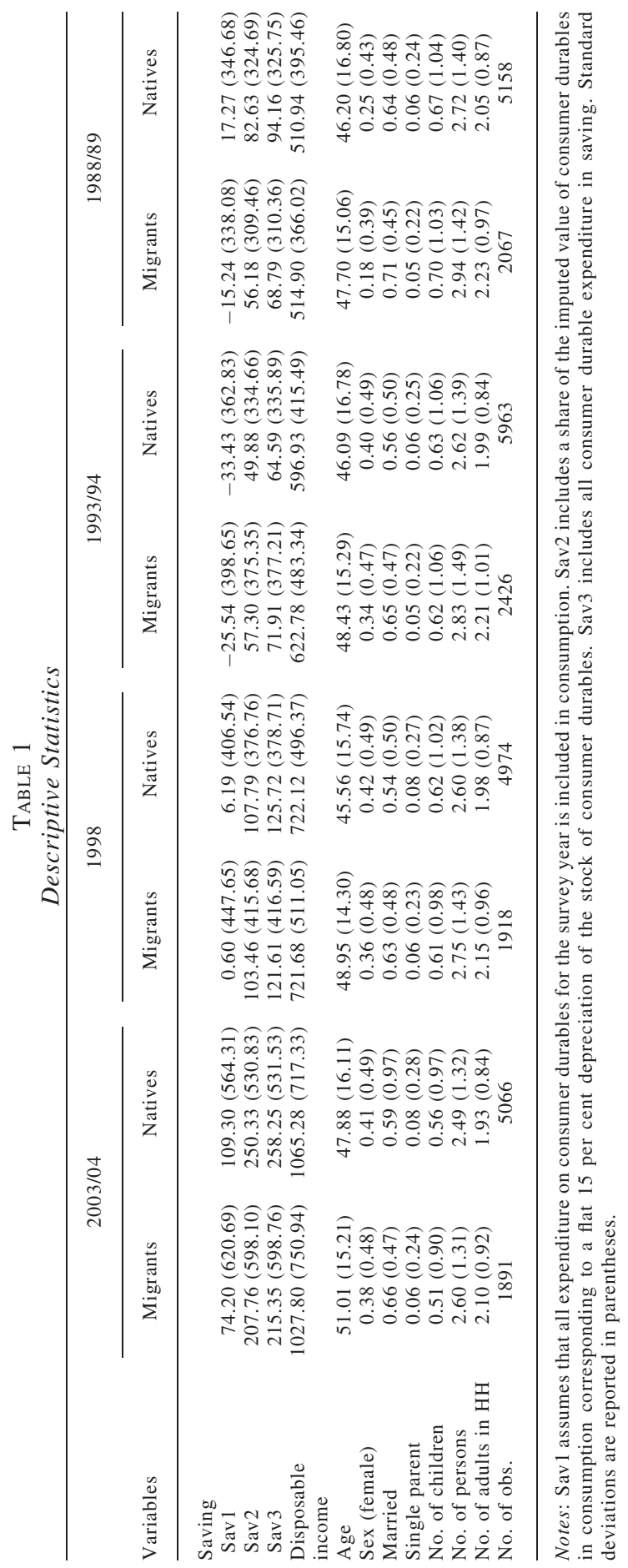


FIGURE 1

Saving Density Functions $\left(S_{\mathrm{m}}\right.$ and $\left.S_{\mathrm{n}}\right)$. Density of Saving of Immigrants and Natives:

(a) 2003/04; (b) 1998; (c) 1993/4; (d) 1988/9.

(a)

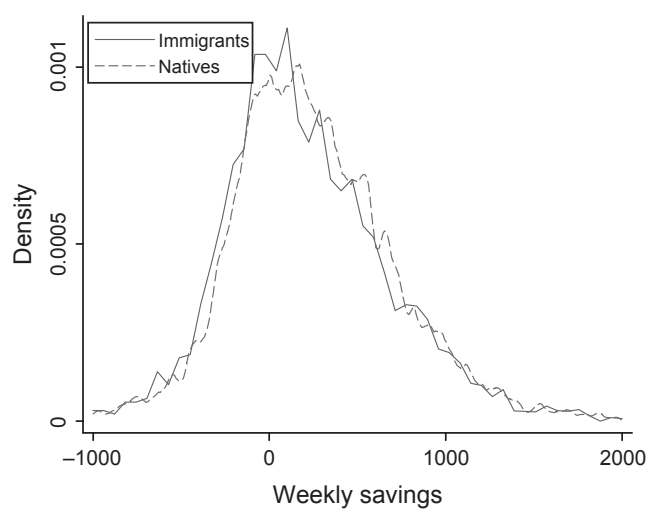

(c)

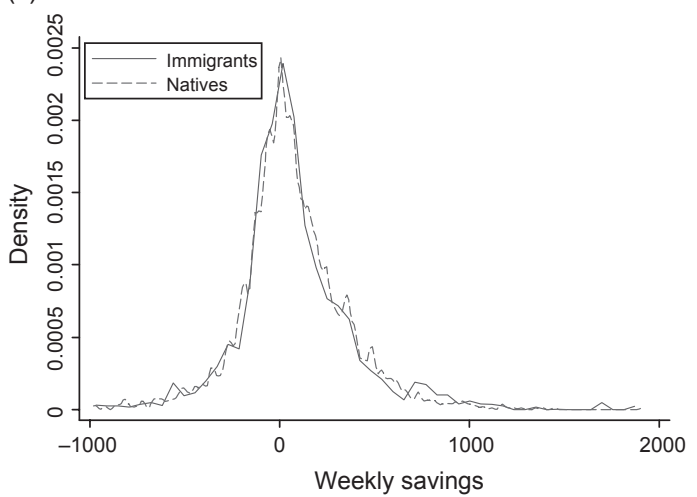

(b)

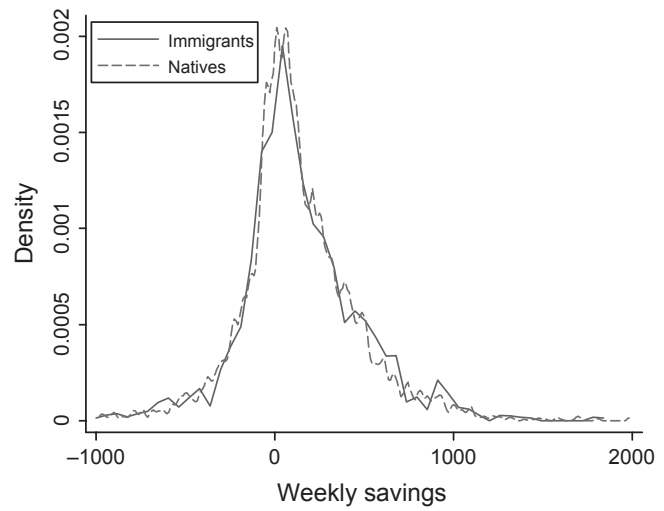

(d)

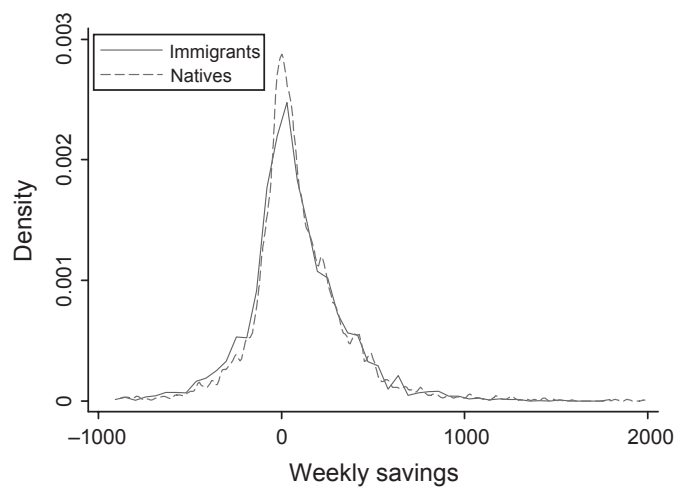

Notes: Saving (in AUS\$) includes all durables (Sav1). For expositional purpose, we truncated saving at either end of the distribution. The regression estimates, however, do not exclude those observations although they are few in number.

again with the exception of $1993 / 94$, consistently reduces the saving gap, generating saving differentials in favour of migrants particularly in the upper half of the distribution. In 2003/04 (Fig. 2a), using covariates reduces the saving gap at each quantile in absolute terms and causes it to turn strongly positive at higher levels. Immigrants save more than natives at the 80th quantile and above. In the intermediate years (1993/94 and 1998), the raw estimates of quantiles suggest that immigrants, in general, save less than natives below the median of the saving distribution and that the differential turns positive above the median. Reweighting (using covariates) increases immigrant saving relative to natives' across the entire distributions in 1988/89 and 1998, while it has an ambiguous effect on the gap in 1993/94. Over time the saving gap changes in favour of migrants at progressively lower points in the saving distribution. In 1988/89, immigrants saved more than natives above the median of the saving distribution while a decade later they did so along the entire distribution while in 1993/94 immigrant saving exceeds natives' at the 85 th quantile and above. These mappings illustrate that a large part of the raw saving differential (in 
FIGURE 2

Unconditional Saving Gaps in $\$\left(S_{\mathrm{m}}-S_{\mathrm{n}}\right)$.
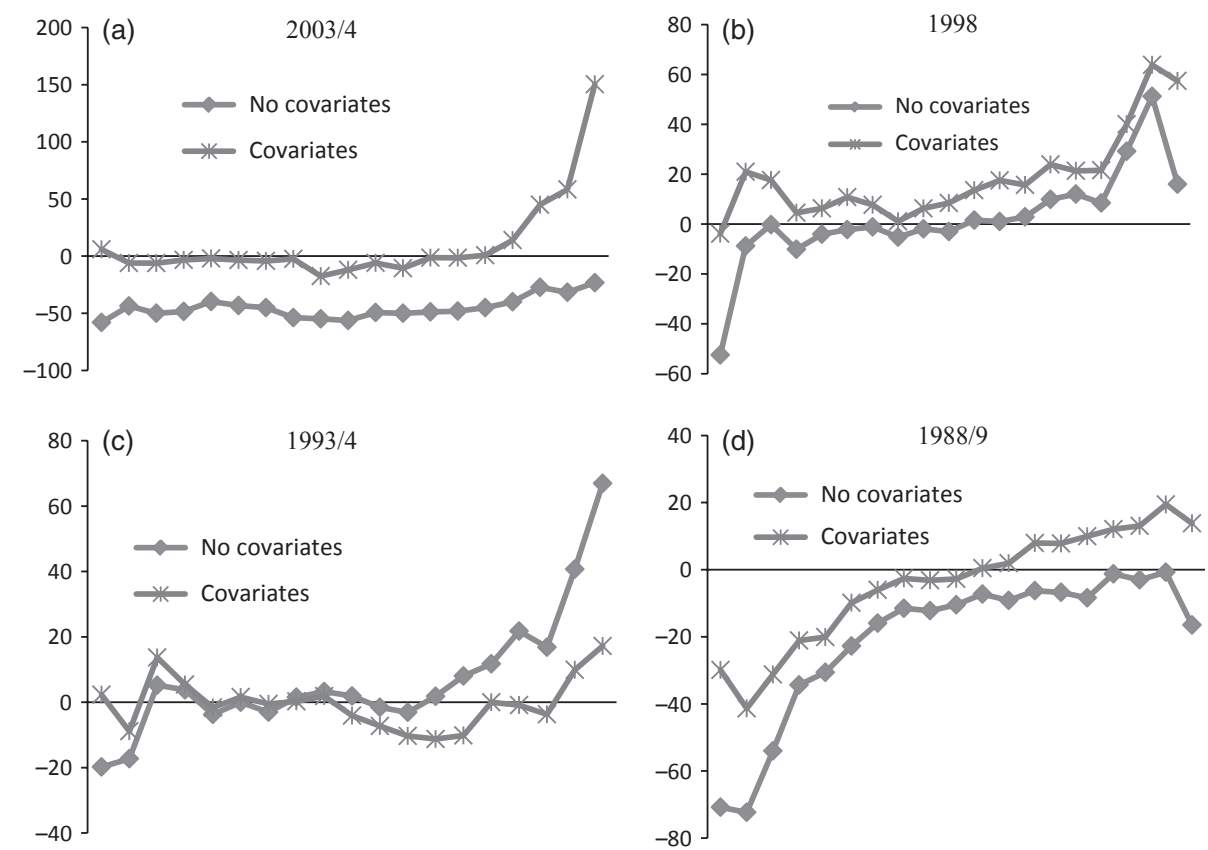

Notes: In (a)-(d), the no covariates locus represents the raw saving gap (in AUS\$) at different quantiles (5th-95th quantiles). The covariates locus maps the saving gap at different quantiles using the weighting procedure described in Firpo (2007).

favour of native households) can be accounted for by household characteristics. They also indicate similarities in the raw saving differential between 2003/04 and 1988/89, as well as between 1993/94 and 1998. Thus, while there is a convergence of saving from $1988 / 89$ to $1993 / 94$ and 1998 , at least above the median of the distribution, we see the trend reverse in 2003/04. That pattern is qualitatively consistent across the three sets of saving figures presented in the descriptive statistics.

\section{Estimation Strategy}

Our empirical findings are based on three successive steps. The first step employs ordinary least squares (OLS) as baseline regression to identify the saving differential and to isolate the factors that contribute to it. The second step uses QR methods to identify the saving differential at different points of the conditional saving distribution. The third step applies the quantile-based decomposition technique of Machado and Mata (2005) to explore the nature of the saving gap between immigrant and native-born households. This decomposition method separates the effects of the differences in the distributions of immigrant and native characteristics from any differences in the returns to those characteristics.

To compare the saving patterns of immigrant and native households, we estimate OLS functions of the following form:

$$
S_{i}=X_{i}^{\prime} \beta_{1}+M_{i} \beta_{2}+\varepsilon_{i}
$$

where subscript $i$ refers to household, $X$ is a vector of household demographic and socioeconomic characteristics including income, $\beta_{1}$ is the corresponding vector of coefficients, $M$ is an immigration dummy variable equal to one if a household head is born overseas and zero otherwise. $\beta_{2}$ measures the saving differential between immigrant and native households. As income is the most important determinant of saving, we examine in detail its effect on the size of coefficient $\beta_{2} . S$ is the saving variable. We 
estimate the flow of income saved rather than the saving rate or the propensity to save as many lowincome households have high dissaving that may dominate the estimates.

The main objective is to ensure that observed differences in saving are not incorrectly attributed to differential saving behaviour when in fact they reflect differences in household characteristics such as income. However, one potential concern regarding income is that it is potentially endogenous and likely to suffer from measurement error. There may be systematic bias in underreporting of income and, hence, of saving at the bottom of the income distribution (see, e.g., Brzozowski \& Crossley, 2011; Meyer \& Sullivan, 2011). To the extent that the reporting bias or measurement errors in income are not the same for immigrants and non-immigrants, we need an exogenous source of variation in income to address the potential endogeneity problem. In the absence of an appropriate instrument, we do not deal with the measurement error or endogeneity of income. Browning and Lusardi (1996) argue that measurement error due to income is unlikely to be a major problem for most agents. Even though the observed income distributions for immigrant and native-born households are very similar, we cannot rule out that the extent of underreporting may differ along the distribution (see Appendix 1 available online, Fig. A1). However, our QR results include different points of the distribution. Hence, any differences in reporting of income between immigrants and native born should be reflected in the QR results.

We also consider the possibility that saving behaviour may be heterogeneous across age groups as saving is likely to vary over the life cycle. For example, Attanasio (1998) reports that a typical saving-age profile displays a pronounced hump, peaking around age 55. The saving-age profile could be an important explanatory factor in the present setting as immigrants face an extended transition period on arrival in Australia. Further, they tend to be older than natives (Table 1). We, therefore, divide the sample of households into three distinct age groups: 20-35, 35-55, and 55-70 years.

Next, we use the QR approach introduced by Koenker and Bassett (1978) to examine the saving behaviour across different points of the saving distribution. QR allows parameter estimates of the marginal effects of the explanatory variables to differ across the quantiles of the dependent variable. The basic QR model specifies the conditional quantile as a linear function of covariates. Following Buchinsky (1998), we specify the $\theta$ th conditional quantile of the saving distribution for the $i$ th household $(i=1,2, \ldots N)$ as

$$
\operatorname{Quant}_{\theta}\left(S_{i} \mid X_{i}, M_{i}\right)=X_{i}^{\prime} \beta_{\theta}+M_{i}^{\prime} \gamma_{\theta}, \quad \theta \in(0,1)
$$

where the coefficient vector $\beta_{\theta}$ represents the returns to covariates at the $\theta$ th quantile, and $\gamma_{\theta}$ is the main parameter of interest. Quant ${ }_{\theta}\left(S_{i} \mid X_{i}, M_{i}\right)$ denotes the quantile of $S_{i}$, conditional on regressor vector $X_{i}$ and $M_{i}$. The $\theta$ th regression quantile $(0<\theta<1)$ of $S$ is the solution to minimising the sum of absolute deviation residuals:

$$
\begin{aligned}
\min _{\beta, \gamma} \frac{1}{n}\left\{\sum_{i: S_{i} \geq x_{i}^{\prime} \beta_{\theta}-M \gamma_{\theta}} \theta\left|S_{i}-X_{i}^{\prime} \beta_{\theta}-M \gamma_{\theta}\right|\right. \\
\left.+\sum_{i: S_{i}<x_{i}^{\prime} \beta_{\theta}-M \gamma_{\theta}}(1-\theta)\left|S_{i}-X_{i}^{\prime} \beta_{\theta}-M \gamma_{\theta}\right|\right\}
\end{aligned}
$$

As the minimisation problem of Equation (3) has no explicit form, it is solved with linear programming methods. We estimate standard errors of the estimates by bootstrapping with 500 repetitions. Estimates obtained from QRs represent the marginal effect of covariates on the $\theta$ th quantile of saving.

\section{(i) Decomposition}

Regressions based on Equations (1) and (3) assume that $\beta_{\theta}$ is equal for immigrant and native households within a given quantile of the saving distributions. This contradicts our working hypothesis that the saving behaviour of the two groups of households may differ, that is, that they respond differently to the exogenous characteristics included in $X$. As the estimated $\beta_{\theta}$ 's are dominated by the Australian-born groups which comprise the majority of the population, they reveal little information about the behaviour of immigrants. At the same time, the distribution of migrants and natives with equal characteristics may differ significantly across quantiles and job types. Superior knowledge of local labour markets as well as local experience and networks enable native workers to obtain better jobs than equally qualified migrant workers. Compared 
with a migrant worker, a native worker may be able to command higher returns from a given set of characteristics, $X_{i}$. Green et al. (2007) find that immigrants are more likely than natives to be overeducated, that is, to be working in lowskilled occupations relative to their qualifications. As the potential returns to education and job experience may differ between the two groups, they are also likely to affect the saving differentials for a given set of characteristics $X$. To isolate the respective influence of characteristics and behaviour, we decompose the saving differential.

The conventional decomposition method introduced by Blinder (1973) and Oaxaca (1973) identifies the source of the difference between the means of two distributions. However, when distributions are skewed as in the present case, it is important to examine the entire distribution. Such an examination can be made with decomposition procedures that are based on the $\mathrm{QR}$ approach. We use the quantile-based decomposition method proposed by Machado and Mata (2005). The Machado-Mata approach, allowing decomposition at each quantile, has gained popularity in recent studies (e.g., Albrecht et al., 2003; Arulampalam et al., 2007; Nguyen et al., 2007). It enables us to decompose the immigrantnative saving differential at each quantile into two components: one component attributable to intergroup differences in the distribution of covariates (characteristics) and the other reflecting differences in the distribution of returns (behaviour). That is, the decomposition enables us to identify the extent to which the saving gap can be attributed, respectively, to the different characteristics of natives and migrants and to the differences in their saving behaviour.

The basic idea of the Machado-Mata decomposition approach is to estimate the whole conditional distribution of saving by a $\mathrm{QR}$, and then to integrate the conditional distribution over the range of covariates to obtain an estimate of the unconditional distribution. It is then possible to estimate counterfactual unconditional distributions to perform the usual decompositions. We are particularly interested in the following counterfactuals:

1 The hypothetical immigrant saving density function that would arise if immigrants had the same characteristics as natives. This enables us to identify the coefficient effect, also known as the returns or saving structure effect, reflecting the influence of behaviour.
2 The hypothetical density function that would arise if immigrants had the same returns to characteristics as natives. This enables us to determine the covariate effect, also known as the composition or endowment effect, reflecting the influence of characteristics.

We construct the respective counterfactual saving distributions of native and migrant households as follows:

1 Estimate QR coefficients $\beta_{\mathrm{m}}$ for each quantile $\theta=0.01, \quad 0.02, \quad \cdots \quad 0.99$, using immigrant household data.

2 Use the native household data to generate the fitted values $S^{*}(\theta)=X_{\mathrm{n}} \beta_{\mathrm{m}}(\theta)$. For each $\theta$, this generates $N_{\mathrm{n}}$ fitted values, where $N_{\mathrm{n}}$ is the size of the native subsample.

3 Select $N$ elements at random from the elements of $S^{*}(\theta)$ for each $\theta$ and stack these into a $99 \times N$ element vector $S^{*}$. The empirical cumulative distribution function (CDF) of these values is the estimated counterfactual distribution of native households.

4 Estimate immigrant counterfactual density by reversing the roles of immigrant and native household data in steps 1 and 2 . That is, use the native dataset to estimate the $\mathrm{QR}$ coefficient and generate the bootstrap data from the immigrant dataset.

Let $S^{\mathrm{m}}(\theta)$ and $S^{\mathrm{n}}(\theta)$ represent the $\theta$ th quantile of the immigrant and native distributions. Then, the difference between their saving distributions at the $\theta$ th quantile is given by

$$
\begin{aligned}
S^{\mathrm{m}}(\theta)-S^{\mathrm{n}}(\theta) \equiv & \left\{S^{\mathrm{m}}(\theta)-S^{*}(\theta)\right\}+\left\{S^{*}(\theta)\right. \\
& \left.-S^{\mathrm{n}}(\theta)\right\} .
\end{aligned}
$$

We use the immigrant counterfactual density to obtain:

$$
\begin{aligned}
X_{\mathrm{m}} \beta_{\mathrm{m}}(\theta)-X_{\mathrm{n}} \beta_{\mathrm{n}}(\theta)= & X_{\mathrm{m}} \beta_{\mathrm{m}}(\theta)-X_{\mathrm{n}} \beta_{\mathrm{m}}(\theta) \\
& +X_{\mathrm{n}} \beta_{\mathrm{m}}(\theta)-X_{\mathrm{n}} \beta_{\mathrm{n}}(\theta) \\
= & X_{\mathrm{n}}\left\{\beta_{\mathrm{m}}(\theta)-\beta_{\mathrm{n}}(\theta)\right\} \\
& +\beta_{\mathrm{m}}(\theta)\left\{X_{\mathrm{m}}-X_{\mathrm{n}}\right\}
\end{aligned}
$$

The first term on the right-hand side of Equation (5) represents the returns or saving structure or coefficient effect: it measures the contribution of different behaviours to the migrant-native saving gap at the $\theta$ th quantile. This represents the contribution of differences in the returns obtained by migrants and natives 
with hypothetically identical characteristics. The second term on the right-hand side is the covariate or endowment or composition effect: it measures the contribution of the different characteristics (covariate values) of immigrant and native households to the saving gap at the $\theta$ th quantile. As we have already accounted for household socioeconomic characteristics, this effect reflects the consequences of unknown dimensions of behaviour. Possible factors that could contribute to the saving structure effect include the difference, by nativity status, in household spending on human capital, particularly on investment in children's education. Card (2005), for example, finds that immigrant households invest more than native born in their children's education. Another factor is the role of interfamily assistance in smoothing consumption. The development literature (e.g., Islam \& Maitra, 2012) notes that consumption smoothing takes place at the community, village or kinship level. At the same time, by virtue of their relatively short residency and limited employment and credit histories, immigrants have less ready access to such interfamily assistance and lending institutions in the host country. Therefore, differential reliance by immigrants and natives on non-market methods of support and financial assistance may account for systematic differences in saving by nativity status. A third factor relates to differences in attitudes or preferences regarding wealth accumulation. For example, it is probable that the very different motivations and experiences of immigrants and natives may give rise to different levels of risk aversion and distrust towards institutions, financial and other. ${ }^{3}$ We leave these conjectures for future research. For present purposes, we interpret the saving structure or returns effect as reflecting differential preferences or attitudes to saving by immigrant and native households. These behavioural differences may reflect a combination of the factors mentioned above as well as other influences.

\section{Results}

We report results based on OLS and QR methods in subsection (i). Results for different subgroups based on age, nativity and family status are reported in subsection (ii).

\footnotetext{
${ }^{3}$ Barsky et al. (2002) provide a similar argument of wealth accumulation by blacks and whites in America.
}

Finally, the decomposition results using the Machado-Mata approach are presented in subsection (iii).

\section{(i) OLS and QR Results}

To document the importance of demographic and socioeconomic characteristics in determining the saving differential between migrants and native born, we report in Table 2 a set of baseline OLS regression results of Equation (1). These average effects disguise potentially significant variation across different points of the distribution. That heterogeneity of saving behaviour is captured by the QR results. The baseline regression results cover the three different measures of weekly household saving for the four survey years. All the regressions include household demographic and socioeconomic characteristics such as age, sex, marital status, education, employment status of household head, number of children and number of adults, and type of family (nuclear or joint) as well as state fixed effects to capture variation across different geographical locations. Two sets of coefficient estimates are presented with (even-numbered columns) and without controlling for income (odd-numbered columns).

The main finding of the baseline OLS results is the strong influence of income on saving, however defined. Controlling for all characteristics other than income reveals significant saving gaps in favour of Australian-born households, except in 1993/94. These saving gaps are substantial and persistent across time and treatment of expenditure on durables. Conversely, once income is included among the controls the saving gaps reverse sign in favour of immigrant households. To illustrate, column 1 of Table 2 shows that in 2003/04 immigrant households saved \$40-\$56 less per week than native-born households. In contrast, column 2, which controls for income, records positive saving differentials of \$19-\$25 per week in favour of immigrants. The income differential enjoyed by native-born households is associated with a reversal in the saving gap in their favour to the tune of $\$ 59-\$ 81$ per week. It follows that the relatively low measured immigrant saving does not reflect immigrant myopia, or parsimony of native-born households. Rather, the present findings strongly suggest that this difference is largely attributable to differences in household income. At a given income level immigrants 


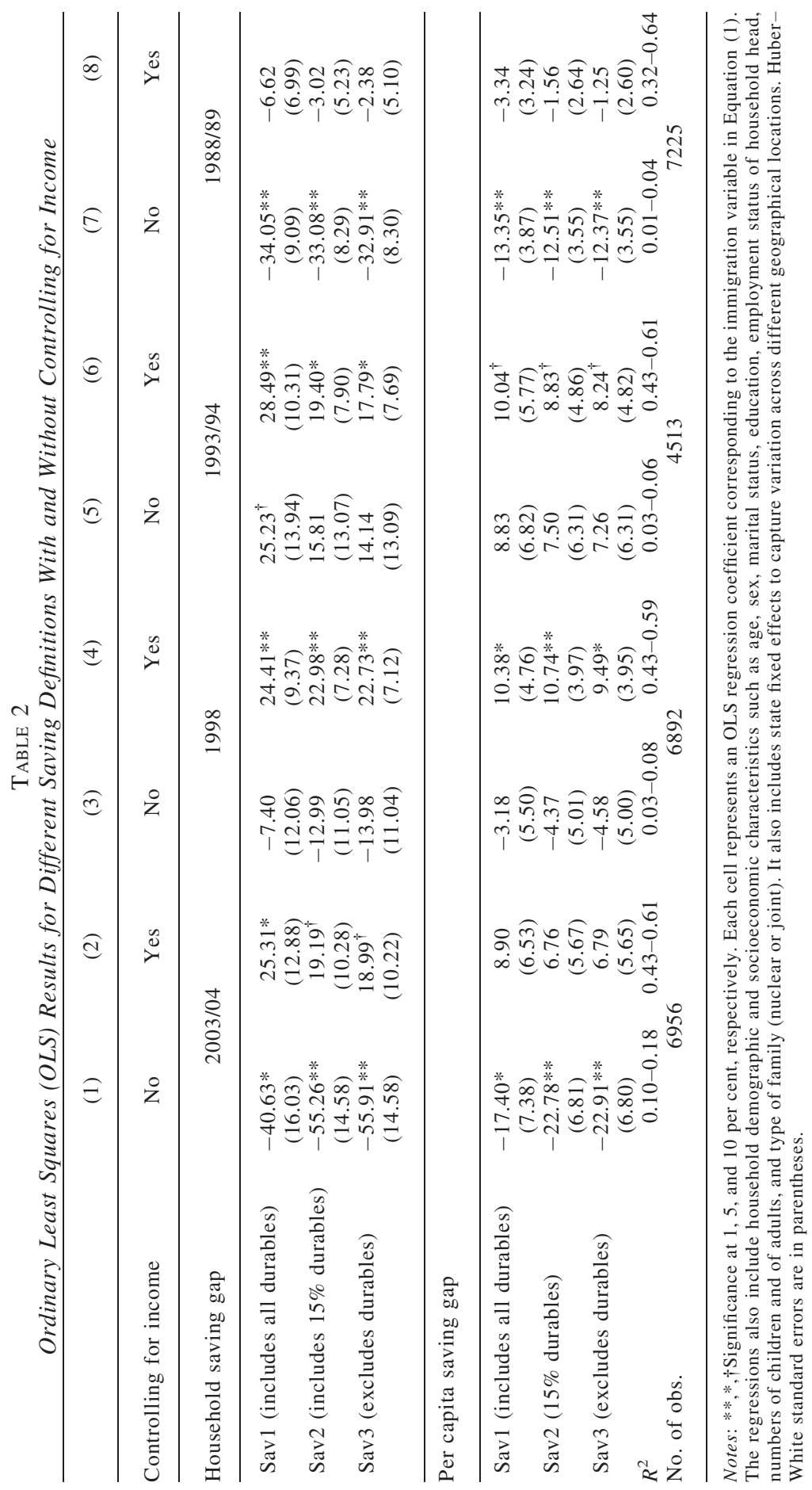


consistently save more than natives, both at the level of the household and per capita. ${ }^{4}$

A relevant contentious issue is the potential endogeneity of income. The tails of the distribution could be biased due to underreporting of income by low-income households as suggested in recent studies (Brzozowski \& Crossley, 2011; Meyer \& Sullivan, 2011). The former find evidence of underreporting of income by responding low-income households and survey non-response by low-income Canadian households. They conclude that the resulting biases are mutually offsetting: underreporting leads to underestimates of the incomes of the poor, while non-random survey non-response leads to overestimates of the incomes of the poor.

When comparing natives and immigrants, and controlling for covariates, the measurement error should cause a bias in our estimates of the coefficients of income and migrant variables only if there is a systematic difference in the way the two groups report their incomes. We do not have any evidence to support that such a difference exists. Nor are we aware of any studies addressing the specific issue that migrants systematically underreport their income. To the extent that migrants are concentrated among low-income households, Brzozowski and Crossley (2011) suggest that there is a possibility of bias in coefficient estimates of the migrant variable. However, our data do not support this conjecture. Figure 1 indicates that native and migrant saving is similar at the tails while the gap is rather more pronounced in the middle of the distribution. In Appendix 1 (available online) Figure A1, we show that the distribution of income at the lower end is also similar for immigrants and native born. This similarity does not preclude the existence of differences in underreporting. However, these figures indicate that bias due to potential underreporting of income by migrants is unlikely to dominate the results.

A natural question is why should immigrants, in particular, intentionally misreport their earnings in household surveys? On one hand, there is very little direct benefit for an individual, whether migrant or native born, in underreporting their income. Unlike in dealings with official authorities, misrepresentations in surveys do not affect

\footnotetext{
4 The exception is the year 1988/89, but those coefficient estimates are not significant statistically or economically.
}

the individual's tax burden or transfer payments, nor are there any penalties associated with such misrepresentations.

In the hypothetical scenario that migrants had strong propensities to misreport their incomes in household surveys, it is not clear how one could correct the resulting bias in estimates without further knowledge of the nature of the bias. If migrants systematically underreport their incomes compared with natives, then measured saving for migrants is underreported as well. In that case we would be estimating the lower bound of the coefficient of the migrant variable in the saving equation. But when we control for income, the effect of possible underreporting on the direction of the coefficients of the income and migrant variables in the saving regression is not clear. Alternatively, if income underreporting is particularly concentrated among low-income migrant households, then failure to adjust for underreporting would lead to an upward biased estimate of the income and immigrant coefficients. As the actual pattern of underreporting is unknown, any adjustment for underreporting of income would tend to impart an upward bias to estimates of the saving gap between migrants and natives.

Finally, income is likely to be endogenous because unobserved factors that influence income are also likely to influence individual saving behaviour. In the absence of panel data or any exogenous variation in income, the coefficient of income is subject to bias, and the results should be interpreted as such. If the unobservables that influence both income and saving are distributed evenly between migrant and native households, we see no potential bias in the resulting coefficient of migrant due to endogeneity of income.

Table 3 reports QR estimates conditional on household characteristics, following Koenker and Bassett (1978). Consistent with the OLS results in Table 2, we report estimates with and without controlling for income. Results using full controls (conditioning on income) show that immigrant households save more at each quantile of the saving distribution, except for 1988/89. The saving differential is generally larger above the median of the distribution (except in 1998 when the largest difference is observed at the 25th quantile), and that difference increases with time. For example, at the 75 th quantile, the immigrantnative weekly conditional saving difference is only $\$ 3.05$ in $1988 / 89$ and more than five times as large $(\$ 17.43)$ in 2003/04. Per capita saving 


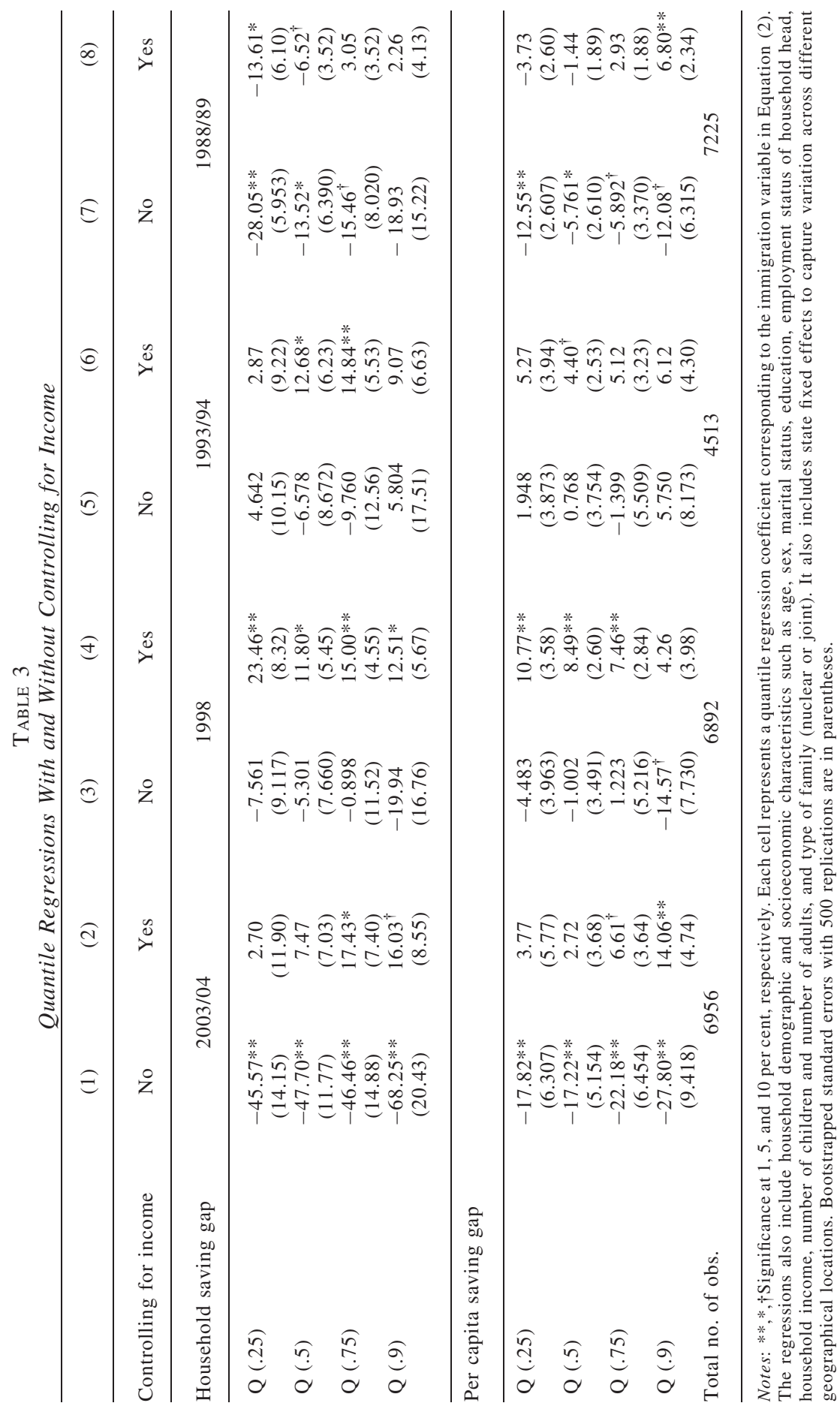


FIGURE 3

Immigrant - Native Saving Gap. Difference in saving: (a) 2003; (b) 1998; (c) 1993; (d) 1988.
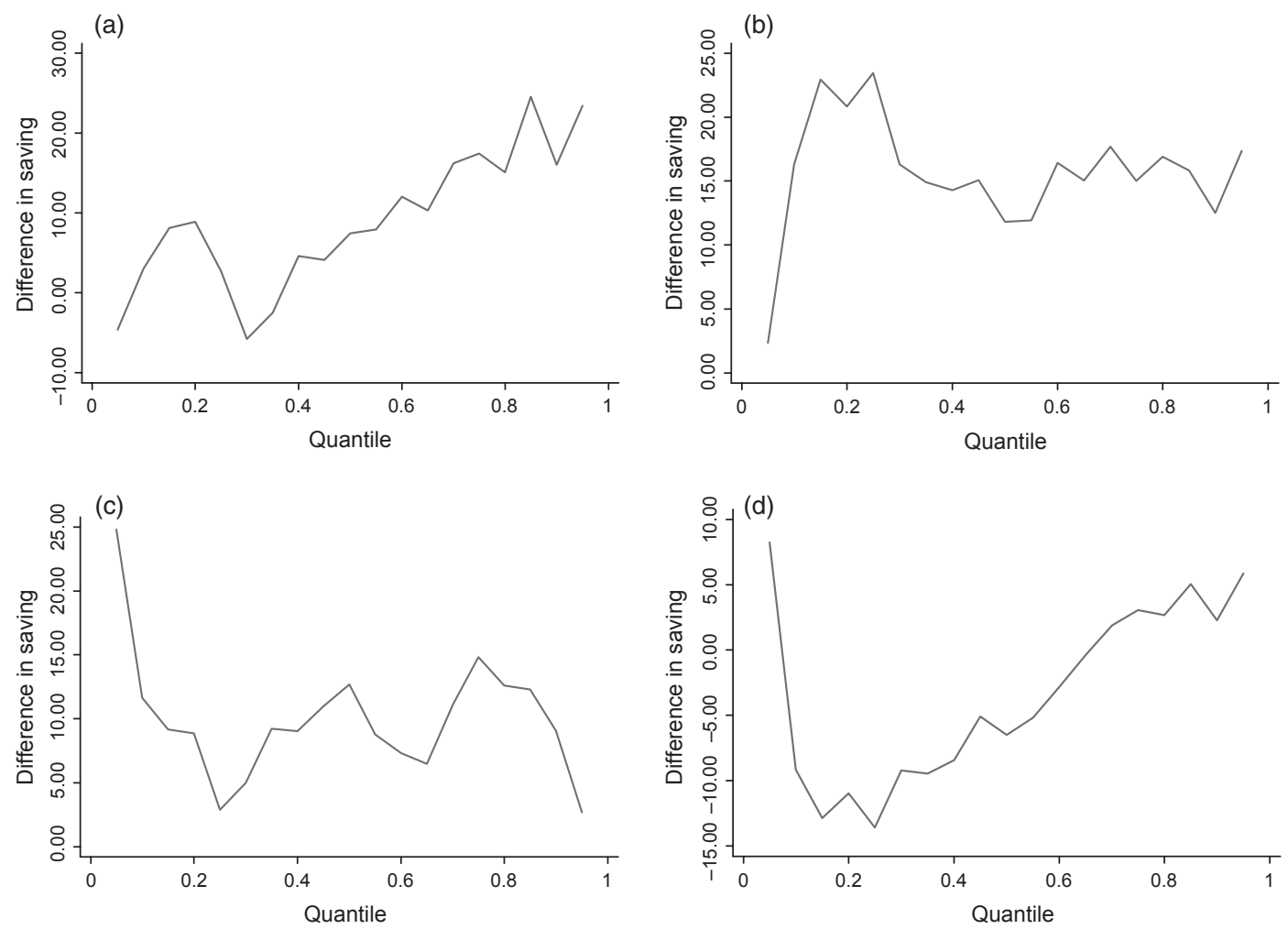

Notes: The graphs (a-d) use the quantile regression (QR) coefficient for each percentile of the distribution, and then plot the coefficients against percentiles. The solid lines plot the estimates of the (conditional) QR coefficients for each percentile of the saving distributions. The difference in weekly saving is defined as the saving of immigrant minus saving of native-born Australian households.

reveals a qualitatively similar picture. Immigrant households' per capita weekly saving at the 90th percentile in $1988 / 89$ was $\$ 6.8$ higher than that of natives. By 2003/04, that differential had more than doubled, to approximately $\$ 14$. Overall, the QR regression results confirm that controlling for income matters, and that this is true for different points of the distribution. The sign of the saving gap between migrants and native-born reverses, with the exception of 1993/94, for all groups of households when we take income into account. Figure $3 \mathrm{a}-\mathrm{d}$ plots the estimates of the conditional (on income) QR coefficients for each percentile of the saving distribution. The figures show that all the coefficients are positive with exceptions occurring in 1988/89 for the lower half of the distribution and in 2003/04 below the 30th quantile. This means that for all other observations, the conditional saving of immigrants exceeds that of native-born households at each percentile of the saving distribution.

\section{(ii) Results for Different Subgroups}

The scope for examination of the saving behaviour of subgroups is limited by the small size of the relevant samples. This examination is, therefore, restricted to estimations by OLS. We do not report QR regression results because of the small sample size of each subgroup. Table 4 reports coefficients of the immigrant dummy for different age groups using the full set of household characteristics, including 
TABLE 4

Nativity Saving Gap by Age of Household Head (OLS Estimates)

(1)
(3)

(4)

\begin{tabular}{|c|c|c|c|c|}
\hline Household saving gap & $2003 / 04$ & 1998 & $1993 / 94$ & $1988 / 89$ \\
\hline Age $20-35$ & $-19.75(21.74)$ & $-17.64(15.35)$ & $32.38 *(15.26)$ & $4.90(10.03)$ \\
\hline Age $35-55$ & $34.65 *(16.20)$ & $44.03 * *(11.29)$ & $14.74(12.46)$ & $11.13(8.48)$ \\
\hline Age 55-70 & $31.55(23.16)$ & $45.14 * *(14.39)$ & $48.46 * *(18.43)$ & $-7.16(10.45)$ \\
\hline \multicolumn{5}{|l|}{ Per capita saving gap } \\
\hline Age $20-35$ & $-14.25(11.05)$ & $-10.79(7.48)$ & $15.31 *(7.22)$ & $1.65(5.35)$ \\
\hline Age $35-55$ & $11.15(7.29)$ & $18.60 * *(6.75)$ & $6.77(8.96)$ & $3.75(3.96)$ \\
\hline Age $55-70$ & $25.98^{\dagger}(15.19)$ & $27.86 * *(8.06)$ & $18.22 *(8.51)$ & $-4.01(5.32)$ \\
\hline$R^{2}$ & $0.54-0.61$ & $0.44-0.48$ & $0.44-0.61$ & $0.47-0.69$ \\
\hline
\end{tabular}

Notes: $* * * *, \dagger$ Significance at 1,5 , and 10 per cent, respectively. Each cell represents an OLS regression coefficient corresponding to the immigration variable in Equation (1) for the respective age group. The regressions also include household demographic and socioeconomic characteristics such as age, sex, marital status, education, employment status of household head, household income, number of children and number of adults, and type of family (nuclear or joint). It also includes state fixed effects to capture variation across different geographical locations. Huber-White standard errors are in parentheses. OLS, ordinary least squares.

income. We split the sample by age of household head as reported in the survey as a considerable proportion of immigrants are at their transitional stages. This decomposition of the sample also reduces the impact of labour market entry and exit. It is immediately apparent that relative immigrant saving is not consistent across age groups or over time. Abstracting from the 1993/94 figures, relative saving by the young has decreased over time, both at the household level and per capita. Saving of the middle group (age 35-55) and old group (55-70) has trended upwards along an inverted U-shape, decreasing from 1998 to 2003/04. While most immigrants save more than natives when conditioning on income and other characteristics, it is the younger immigrants who are saving less than the native born during the latter part of the observation period. This age group would have arrived only recently in Australia and established a new household. The associated lumpy one-off expenses would be expected to depress their saving during the establishment phase. ${ }^{5}$ It is,

${ }^{5}$ Doiron and Guttmann (2009, p. 38) identify age as one of the wealth-enhancing variables. This is consistent with our finding of variable saving propensities across the age distribution. therefore, not surprising that their saving is low in comparison with young native-born Australians.

We also construct a quasi-panel of synthetic cohorts using the HES cross-sectional datasets. The results are discussed in Appendix 2 available online. This synthetic cohort analysis is constrained by small sample size of each cohort by survey year but supports our earlier findings: after conditioning on income all immigrants except for the younger cohorts tend to save more than the native born.

To examine the robustness of our findings with respect to type of household, we distinguish between households composed of singles and couples and investigate the relative saving behaviour of these subgroups of migrant and nativeborn households.

$$
\begin{aligned}
S_{i}= & X_{i}^{\prime} \partial_{1}+M_{i} \partial_{2}+\text { Single }_{i} \times \partial_{3}+M_{i} \times \text { Single }_{i} \\
& \times \partial_{4}+v_{i}
\end{aligned}
$$

'Single ${ }_{i}$ ' is a dummy variable indicating whether the household is composed of a single person or headed by a couple. The regressions have been run with the three alternative saving measures and with or without conditioning for income. We report results for $\delta_{2}, \delta_{3}$ and $\delta_{4}$ for the 
FIGURE 4

Decomposition of the Saving Gap $\left(S_{\mathrm{m}}-S_{\mathrm{n}}\right)$. Decomposition of Differences in Distribution: (a) 2003; (b) 1998/9; (c) $1993 ;$ (d) 1988 .

(a)

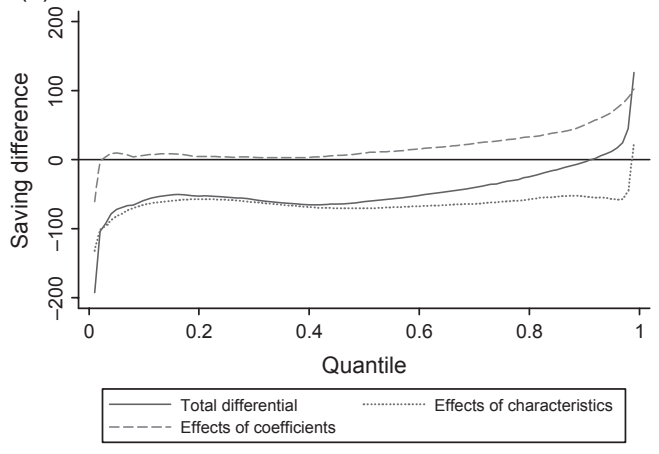

(c)

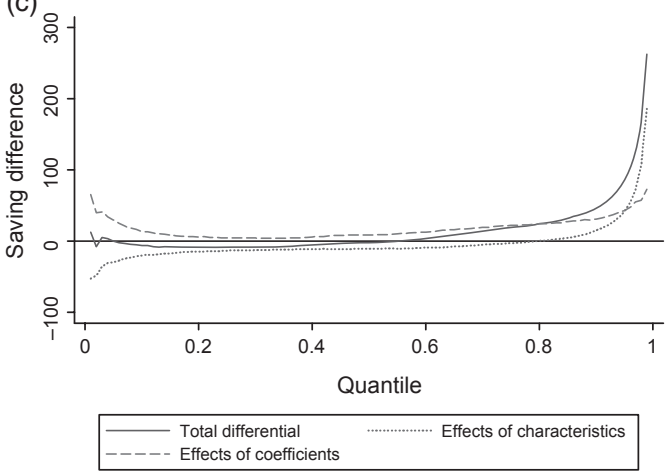

(b)

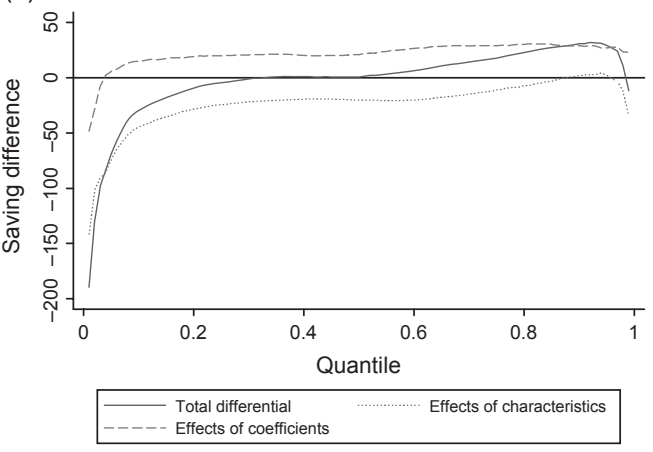

(d)

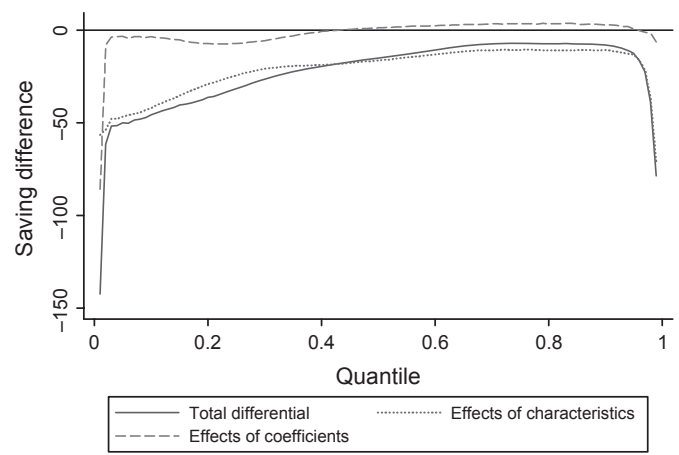

Notes: Graphs (a)-(d) plot the regression coefficients using the Machado-Mata (2005) quantile regression decomposition procedure. The 'effects of characteristics', also known as the 'composition effect', identifies that part of the saving gap that is due to differences in characteristics, while the 'effect of coefficients', also known as 'structure effect', identifies the difference in the returns to the characteristics. 'Total differential' is the sum of composition effect and structure effect. The solid straight line is the horizontal reference line at zero.

four survey years in our sample in online Appendix 1 (Table A1). Overall, single households save more, but there is no evidence that single immigrant households save consistently less or more than their native counterparts. The coefficient $\delta_{4}$ becomes statistically insignificant after controlling for income. To test the robustness of these findings, we also ran separate regressions for the single and couple subsamples to allow for different returns to characteristics across these two types of household. These experiments did not change the results in any substantive way.
Country of origin is another potentially important determinant of immigrant saving. However, existing empirical evidence is mixed. While Carroll et al. (1999) observe significant differences by country of origin for US migrants, their earlier study (Carroll et al., 1994) found no such evidence for Canadian migrants. Cobb-Clark and Hildebrand (2009) report that country of origin is associated with considerable variation in net worth and asset portfolios of migrants in Australia. In contrast, Doiron and Guttmann (2009) observe that generally nativity wealth differentials are statisti- 
cally insignificant across country of origin. Data constraints prevent us from systematically controlling for country of origin in a meaningful manner for the entire observation period. However, as a first approximation, we can differentiate between English speaking (ESB) and non-English speaking (NSB) countries of origin. Information on this attribute is provided in the 2003/04 HES. ${ }^{6}$ Differentiating the sample according to language background suggests that NSB migrants save significantly more than their ESB counterparts (Appendix 1 available online, Table A2). This finding is robust with respect to the treatment of expenditure on consumer durables that is reflected in the different saving measures.

\section{(iii) Decomposition Results}

The results from Machado-Mata decompositions are shown in Figure 4a-d. Detailed results with confidence bands for the coefficient estimates for each quantile are reported in online Appendix 1, Figure A2a-d. The composition effects associated with an $X$ variable correspond to the term $\beta_{\mathrm{m}}(\theta)\left(X_{\mathrm{m}}-X_{\mathrm{n}}\right)$. This term represents the component of the saving differential that is due to differences in characteristics. Similarly, the effects of coefficient, or the structure effects, are captured by the term $X_{\mathrm{n}}\left(\beta_{\mathrm{m}}(\theta)-\beta_{\mathrm{n}}(\theta)\right)$. This represents the difference in the returns obtained by immigrant and native households with given characteristics which we attribute to differences in saving behaviour. Figure 4a, for example, shows that in 2003/04, the raw saving gap is in favour of natives until about the 95th percentile. The figure also shows that the role of characteristics/covariates in explaining the saving gap increases as we move up along the saving distribution. The decomposition analysis demonstrates that the negative saving gap is attributable to the different characteristics of the two groups of households. It also indicates that the differ-

\footnotetext{
${ }^{6}$ The earlier Surveys group countries of origin into broad categories such as Other Oceania and Antarctica, North-West Europe, Southern and Eastern Europe and Americas. As these broad country groupings include English speaking as well as non-English speaking countries, we are unable to distinguish reliably between ESB and NESB migrants in those earlier years. Furthermore, these country groupings are not consistent across Surveys, and hence, we cannot construct dummies to control for region of origin in a meaningful way.
}

ences in characteristics between immigrants and natives alone can account for more than the observed raw differences in saving, and that this excess increases significantly in the upper half of the distribution. If immigrants and natives had identical characteristics, the former would have saved more than the latter. The behavioural differences in saving are also stronger in the top quartile. This means that among the poorer households, differences in household characteristics matter more than the differences in returns to those characteristics. However, the dominance of returns effects at the upper end of the distribution means that richer immigrant households display a relatively strong preference towards saving. This behaviour effect (more than) compensates for their inferior income position to generate a positive saving gap.

The decomposition results for 1998 indicate that raw saving differences become positive beyond the median, and they are clearly significant after the 60th quantile. The saving gap can be attributed mostly to the differences in characteristics, the total difference in saving moving in parallel with the composition effect. The composition effect, which captures the saving gap associated with observable characteristics $(X)$, is negative with an absolute value larger than the total saving differential. Again, we find a very flat curve for behavioural differences across the entire distribution, indicating that the relatively strong saving disposition of immigrant households is roughly constant across the different groups of households. We observe qualitatively similar patterns in 1993/94 and 1988/89 (Fig. 4c,d, respectively). In 1993/94, the raw saving difference becomes positive in the vicinity of the median, and there is a sharp increase towards the end of the distribution. The difference is, however, well explained by the differences in characteristics. The saving difference in $1988 / 89$ is well explained by differences in characteristics after the 40th quantile. Although relatively weak, the returns effects or behavioural differences move the measured saving gap slightly in favour of migrant households up to the 95 th quantile.

Overall, these findings suggest that it is the differences in characteristics that drive differences in measured saving, and that these differences have become increasingly prominent in the recent past. The returns effect has also contributed increasingly to the change of the saving differential in favour of migrant house- 
holds. To the extent that the returns effect reflects behavioural differences, immigrant households tend to display higher preference towards saving compared with their native-born counterparts.

\section{$V$ Conclusion}

Our main finding across OLS, QR, semiparametric decomposition and synthetic cohort analyses is that differences in the observed characteristics of migrant and native households account for the relatively low measured saving of migrant households. At the same time, we find that migrant households have a consistently higher propensity to save than native-born households. These seemingly contradictory findings reflect the dominant role of household income in determining household saving. Immigrant households have relatively low incomes, and that depresses their measured saving relative to native-born households notwithstanding their higher propensity to save.

The present findings are consistent with recent work on the portfolio composition (Cobb-Clark \& Hildebrand, 2009) and wealth distribution (Doiron \& Guttmann, 2009) of immigrant and native households in Australia. Those studies identify a nativity wealth gap (of approximately $\$ 162,000$ in favour of native-born couples; Cobb-Clark \& Hildebrand, 2009). The gap characterises the entire wealth distribution even though 'migrants have more wealth-creating characteristics compared with native households' (Doiron \& Guttmann, 2009, p. 33). We resolve this apparent conundrum through explicit recognition of the role of household income in the wealth-generating process which had been noted by Bauer et al. (2011). ${ }^{7}$ Controlling for income, OLS and QR analyses identify the stronger saving behaviour of immigrant households. Semiparametric decomposition techniques demonstrate that this differential saving behaviour exists along virtually the entire saving distribution.

At the most basic level, our results indicate that both sets of explanatory variables - labour market outcomes captured in household charac-

\footnotetext{
7 'For example, immigrants to Australia accumulate more wealth for each dollar of household net income than do native-born Australians' (Bauer et al., 2011). Similarly, Cobb-Clark and Hildebrand (2009, p. 52) noted that 'household wealth is closely related to permanent income'.
}

teristics and cultural and institutional factors as reflected in household behaviour - are important determinants of the nativity saving gap. Labour market outcomes, specifically income, determine the ability to save. They are the single most important determinant of the observed saving gap in favour of native households. At the same time, demographic and other characteristics shape the willingness to save. They play a significant role in explaining the differential saving behaviour of immigrant and native households. Our analysis suggests that the saving differential varies across the saving distribution: it is particularly pronounced at the upper end. The results also corroborate the age-related heterogeneity in immigrant saving behaviour that had been noted by Doiron and Guttmann (2009). Recent younger immigrants tend to save less than their native counterparts, even conditioning on income. This feature is entirely compatible with life-cycle behaviour and the substantial lumpy resource costs of migration and the establishment of a new existence in a different country. The fundamental finding of a positive saving gap in favour of immigrants at a given level of income applies to households as well as on a per capita basis. It is robust over time and household composition and across different treatments of consumer durables reflected in the alternative specifications of consumption spending.

The raw saving and wealth data obscure important differences in the underlying saving behaviour of immigrant and native-born households. To the extent that saving behaviour is a consideration in the formulation of immigration policy, the raw data should be treated with care and circumspection. On the positive side, policies that facilitate the labour market assimilation of migrants are likely to yield a non-trivial dividend in promoting national savings and, thus, easing the pressure on Australia's federal budget and current account balances.

\section{Supporting Information}

Additional Supporting Information may be found in the online version of this article:

\section{Data S1 Datasets and Codes}

\section{REFERENCES}

ABS (2008), Experimental Estimates of Imputed Rent, Australia, Cat. No. 6540.0. Australian Bureau of Statistics, Canberra. 
Albrecht, J.W., Bjorkland, A. and Vroman, S.B. (2003), 'Is There a Glass Ceiling in Sweden', Journal of Labor Economics, 21, 147-77.

Amuedo-Dorantes, C. and Pozo, S. (2002), 'Precautionary Savings by Young Immigrants and Young Natives', Southern Economic Journal, 69, $48-71$.

Arulampalam, W., Booth, A.L. and Bryan, M.L. (2007), 'Is There a Glass Ceiling over Europe? Exploring the Gender Pay Gap across the Wage Distribution', Industrial and Labor Relations Review, 60, 163-86.

Attanasio, O. (1998), 'A Cohort Analysis of Saving Behaviour by US Households', Journal of Human Resources, 33, 575-609.

Barsky, R., Bound, J., Charles, K.K. and Lupton, J.P. (2002), 'Accounting for the Black-White Wealth Gap: A Nonparametric Approach', Journal of the American Statistical Association, American Statistical Association, 97, 663-73.

Bauer, T.K. and Sinning, M.G. (2011), 'The Savings Behavior of Temporary and Permanent Migrants in Germany', Journal of Population Economics, 24, 421-49.

Bauer, T.K., Cobb-Clark, D.A., Hildebrand, V.A. and Sinning, M. (2011), 'A Comparative Analysis of the Nativity Wealth Gap', Economic Inquiry, 19, 9891007.

Blinder, A.S. (1973), 'Wage Discrimination: Reduced Form and Structural Estimates', Journal of Human Resources, 8, 436-55.

Bonin, H., Constant, A., Tatsiramos, K. and Zimmermann, K.F. (2009), 'Native-Migrant Differences in Risk Attitudes', Applied Economics Letters, 16, 1581-6.

Browing, M. and Crossley, T. (2001), 'The Life-cycle Model of Consumption and Saving', Journal of Economic Perspectives, 15, 3-22.

Browning, M. and Lusardi, A. (1996), 'Household Saving: Micro Theories and Micro Facts', Journal of Economic Literature, 34, 1797-855.

Brzozowski, M. and Crossley, T. (2011), 'Viwpoint: Measuring the Well-being of the Poor with Income or Consumption: A Canadian Perspective', Canadian Journal of Economics, 44, 88-106.

Buchinsky, M. (1998), 'The Dynamics of Changes in the Female Wage Distribution in the USA: A Quantile Regression Approach', Journal of Applied Economics, 13, 1-30.

Card, D. (2005), 'Is the New Immigration Really so Bad?', Economic Journal, 115, F300-23.

Carroll, C., Rhee, C. and Rhee, B. (1994), 'Are There Cultural Effects on Saving? Some Cross-sectional Evidence', Quarterly Journal of Economics, 109, 685-99.

Carroll, C., Rhee, B. and Rhee, C. (1999), 'Does Cultural Origin Affect Saving Behavior? Evidence from Immigrants', Economic Development and Cultural Change, 48, 33-50.
Cobb-Clark, D.A. and Hildebrand, V.A. (2006), 'The Wealth And Asset Holdings Of U.S.-Born And Foreign-Born Households: Evidence from SIPP Data', Review of Income and Wealth, 52, 17-42.

Cobb-Clark, D.A. and Hildebrand, V.A. (2009), 'The Asset Portfolios of Native-born and Foreign-born Households', Economic Record, 85, 46-59.

Doiron, D. and Guttmann, R. (2009), 'Wealth Distribution of Migrant and Australian-born Households', Economic Record, 85, 32-45.

Dustmann, C. (1995), 'Savings Behavior of Return Migrants', Zeitschrift für Wirtschats-und. Sozialwissenschaften (ZWS), 115, 511-33.

Dustmann, C. (1997), 'Return Migration, Uncertainty and Precautionary Savings', Journal of Development Economics, 52, 295-316.

Dustmann, C. and Mestres, J. (2010), 'Remittances and Temporary Migration', Journal of Development Economics, 92, 62-70.

Dynan, K.E., Jonathan, S. and Zeldes, S.P. (2004), 'Do the Rich Save More?', Journal of Political Economy, 112, 397-444.

Firpo, S. (2007), 'Efficient Semiparametric Estimation of Quantile Treatment Effects', Econometrica, 75, 259-76.

Galor, O. and Stark, O. (1990), 'Migrants' Savings, the Probability of Return Migration and Migrants' Performance', International Economic Review, 31, 463-7.

Green, C., Kler, P. and Leeves, G. (2007), 'Immigrant Over-education: Evidence from Recent Arrivals to Australia', Economics of Education Review, 26, 42032.

Islam, A. and Maitra, P. (2012), 'Health Shocks and Consumption Smoothing in Rural Households: Does Microcredit have a Role to Play?', Journal of Development Economics, 97, 232-43.

Jalava, J. and Kavonius, I. (2009), 'Measuring the Stock of Consumer Durables and its Implications for Euro Area Savings Ratios', Review of Income and Wealth, 55, 43-56.

Koenker, R. and Bassett, G. (1978), 'Regression Quantiles', Econometrica, 46, 33-50.

Machado, J. and Mata, J. (2005), 'Counterfactual Decomposition of Changes in Wage Distributions Using Quantile Regression', Journal of Applied Econometrics, 20, 445-65.

Maurer, J. and Meier, A. (2008), 'Smooth it like the "Joneses"? Estimating Peer-Group Effects in Intertemporal Consumption Choice', Economic Journal, 118, 454-76.

McDonald, J. and Worswick, C. (1999), 'The Earnings of Immigrant Men in Australia: Assimilation, Cohort Effects and Macroeconomic Conditions', Economic Record, 75, 49-62.

Meyer, B. and Sullivan, J. (2011), 'Further Results on Measuring the Well-being of the Poor using Income and Consumption', Canadian Journal of Economics, 44, 52-87. 
Miller, P. and Neo, L.M. (2003), 'Labour Market Flexibility and Immigrant Adjustment', Economic Record, 79, 336-56.

Nguyen, B., Albrecht, J., Vroman, S. and Westbrook, D. (2007), 'A Quantile Regression Decomposition of Urban-Rural Inequality in Vietnam', Journal of Development Economics, 83, 466-90.

Oaxaca, R. (1973), 'Male-Female Wage Differentials in Urban Labor Markets', International Economic Review, 14, 693-709.
Osili, O. (2007), 'Remittances and savings from international migration: Theory and evidence using a matched sample', Journal of Development Economics, 83, 446-65.

Perozek, M. and Reinsdorf, M. (2002), 'Alternative Measures of Personal Saving', Survey of Current Business, 82, 13-24.

Reinsdorf, M. (2004), 'Alternative Measures of Personal Saving', Survey of Current Business, 84, 17-27. 